\title{
THE EFFECTS OF DIFFERENTIATED RESERVE REQUIREMENT RATIO POLICY ON THE EARTHQUAKE- STRICKEN AREA IN CHINA
}

\author{
Guo Xiaohui* \\ Hebei University
}

Tajul Ariffin Masron

Universiti Sains Malaysia

\begin{abstract}
In June, 2008, the People's Bank of China (PBC) decided to implement Differentiated Reserve Requirement Ratio (DRRR) policy in the earthquake-stricken counties in Sichuan province in order to help the reconstruction of these areas which suffered the big earthquake. The purpose of this study is to examine the role of this DRRR policy on the disaster area. This paper compares the effects of DRRR policy on the earthquake-stricken counties with that of the normal Reserve Requirement Ratio (RRR) on the other counties using panel data analysis during 2008-2011. The results confirm that this preferential DRRR policy can really quicken the recovery process in the earthquake-stricken counties. This DRRR policy reflects that the PBC starts to use differentiated monetary policy to guide credit funds flow to the area which government policy focus on. Monetary policy begins to play a role in adjusting and optimizing economic structure. Due to large regional disparity, the PBC can consider expand the application of this DRRR policy to more less developed regions to make a more coordinated regional economic development in China.
\end{abstract}

Keywords: Differentiated Reserve Requirement Ratio; Earthquake-stricken Counties; Panel Data Analysis.

\section{INTRODUCTION}

In recent years, along with the deepening of economic reform and opening up, to cope with the complicated domestic and international economic situation, the PBC (the People's Bank of China, central bank of China) has begun to make some new attempts to affect the structure of monetary policy. The PBC has introduced Differentiated Reserve Requirement Ratio (DRRR) policy since April 25 ${ }^{\text {th }}, 2004$. The main content of DRRR policy is that the Reserve Requirement Ratio (RRR) applicable to a financial institution will be linked with certain indicators such as its capital adequacy ratio and asset quality.

\footnotetext{
*Corresponding author: Guo Xiaohui, Department of Finance, School of Economics, Hebei University, 071002, Baoding City, Hebei Province, China. Telephone: +0086-13582259027. Email: nlmh6@126.com
} 
The lower the capital adequacy ratio of a financial institution and the higher its NPL (NonPerforming Loan) ratio, a higher RRR will be charged. The initial purpose of this policy is to limit loan expansion of those financial institutions with inadequate capital and poor asset quality, reduce financial risk and maintain financial stability.

DRRR policy said that financial institutions whose capital adequacy ratios were below $4 \%$ would apply the DRRR $0.5 \%$ higher than normal level ${ }^{1}$. Since this policy applied, the Agricultural Bank of China and 38 joint-stock banks and city commercial banks such as Guangdong Development Bank, China Everbright Bank and Shenzhen Development Bank have been applied DRRR $0.5 \%$ higher than normal level as their loan growth is too fast and the risk is too high.

Figure 1: Differentiated Reserve Requirement Ratio in China from 2008 to 2012

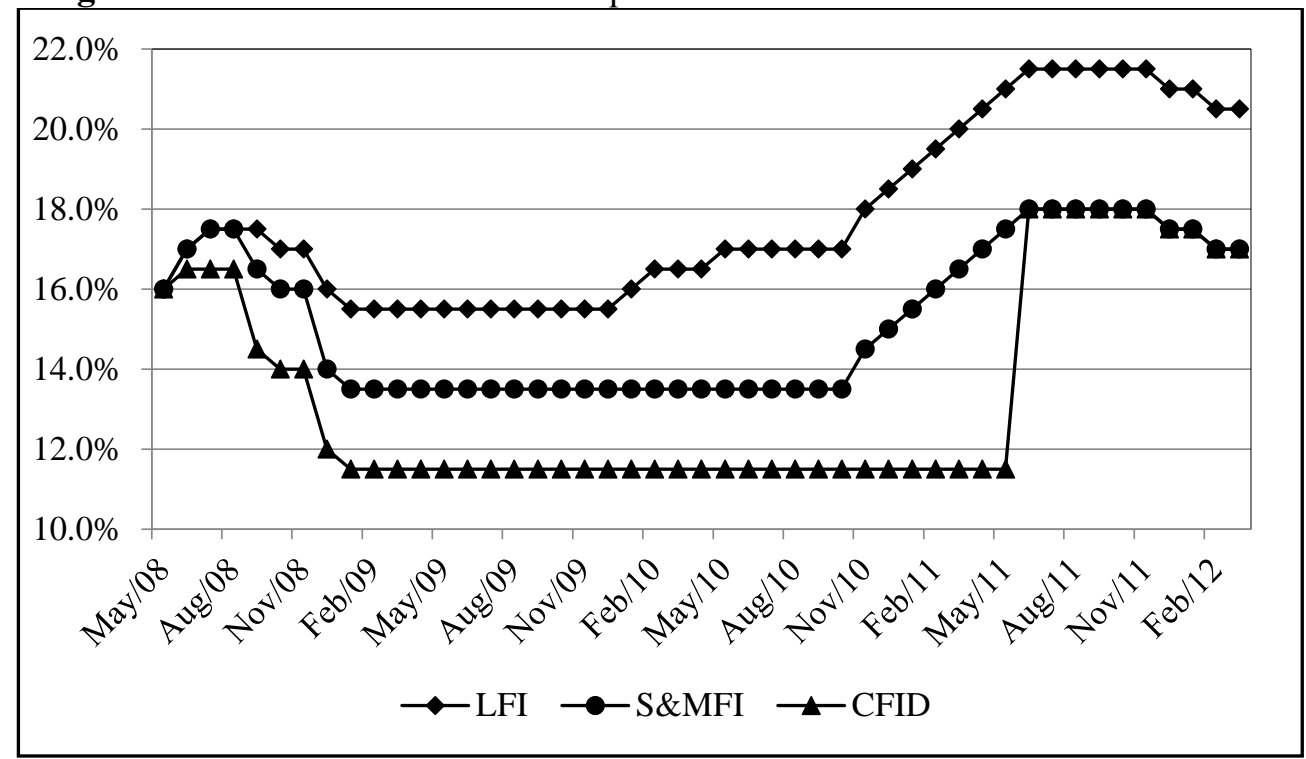

Notes: LFI: Reserve Requirement Ratio of Large Financial institutions. S\&MFI: Reserve Requirement Ratio of Small and Medium sized Financial Institutions. CFID: Reserve Requirement Ratio of Corporate Financial Institutions in Disaster area (39 counties).

Sources: The People's Bank of China

In practice, the PBC has also tried to implement DRRR policy based on regions and the structure of credit to continuously extend the application of DRRR policy. Since September $21^{\text {st }}, 2003$, all financial institutions that took deposits from the public have had to meet a uniform RRR of 7 percent, with the exception of the Urban and Rural Credit Cooperatives that still abide by the 6 percent standard. To support the development of rural area, the PBC did not raise the RRR of Rural Credit Cooperative until 2006. On May

\footnotetext{
${ }^{1}$ The People' Bank of China: http://www.pbc.gov.cn/
} 
$12^{\text {th }}, 2008$, a big earthquake hit Sichuan province and made lots of damage. To support the reconstruction of the disaster area, the PBC decided to apply DRRR a little lower than normal level to corporate financial institutions in 39 counties in Sichuan province that suffered most in the earthquake on June $8^{\text {th }}, 2008$ (see Figure 1). The PBC also declared that this preferential DRRR would not be raised in the disaster area until June, 2011.

Global financial crisis happened in 2008 made the domestic and overseas economic condition become much more complicated. Facing this situation, the PBC decided to apply DRRR to different sizes of financial institutions. On September $25^{\text {th }}, 2008$, the PBC applied DRRR to Large banks and Small \& Medium sized banks (S\&M sized banks). Large banks applied the DRRR 1\% higher than S\&M sized banks. Large banks occupy a bigger market shares, applying a higher DRRR is helpful for the PBC to control money and credit supply. Considering most of loans made by S\&M sized banks flow to S\&M sized enterprises (China Banking Regulatory Commission Annual Report 201122), the PBC applies a little lower DRRR to S\&M sized banks so as to solve the difficulty of financing in S\&M sized enterprises. Currently large and S\&M sized banks apply Differentiated Deposit Reserve Ratio separately (see Figure 1).

The initial purpose of DRRR policy is to limit the loan expansion and reduce financial risk. Afterwards, the PBC tries to use this monetary policy instrument to promote economy growth in certain regions (such as the earthquake-stricken area) and adjust the credit structure (DRRR policy to Large and S\&M sized bank). If the practice can prove that this policy plays an important role in these areas as expected, then the implementation of DRRR policy has a significant meaning to the PBC: first, the shortcoming of traditional monetary policy is that "one size fit all" practice doesn't consider the unbalance of regional economies. But to some extent this DRRR policy can solve or at least mitigate this problem. Second, the PBC can use this policy to adjust the structure of credit. For example, they can apply a higher DRRR to large banks to curb inflation while at the same time implementing a lower DRRR to S\&M sized banks to solve the difficulty of financing in $\mathrm{S} \& \mathrm{M}$ sized enterprises.

Therefore, in this study, we will use the earthquake-stricken area to do case study so as to examine the structural effects of DRRR policy ${ }^{3}$ on promoting the development of certain regions. The organization of this study is as follows: the next section discusses briefly literature review. Section three devotes on methodology and section four highlights the empirical results. Section five is conclusion and limitations.

\footnotetext{
2 "China Banking Regulatory Commission Annual Report 2011"is vailable on: http: //www.cbrc.gov.cn.

${ }^{3}$ Another paper will use large and S\&M sized bank to do case study in order to examine the effects of DRRR policy on the adjustment of the credit structure.
} 


\section{LITERATURE REVIEW}

The traditional description of monetary policy generally emphasizes the reserve requirement constraint on banks. In this story, banks are an important link in the transmission of monetary policy as changes in bank reserves affect the quantity of reservable deposits held by banks (Peek and Rosengren, 1995). Raising the reserve requirement constraint can limit monetary growth and squeeze excess reserves if not fully neutralized, potentially limiting banks' capacity to lend over time (Ma, Yan and Liu, 2011).

After the last financial crisis, reserve requirements receive particular interest in the advanced economies and emerging market economies. A number of literature focuses on the ability of reserve requirements to achieve financial or price stability (Kasyhap and Stein, 2012; Ireland, 2012; Reinhart and Rogoff, 2013; Cañón and Margaretic, 2014; Hoffmann and Löffler, 2014; Glocker and Towbin, 2015). In this regard, the literature also examines the effects of reserve requirements on credit and macro-economy.

It is generally accepted that reserve requirements act as a tax on banks and thus hurt their profits, affecting cost of credit and possibly inducing them to widen the loan-deposit rate spread (Borio and Disyatat, 2009; Montoro and Moreno, 2011; Walsh, 2012). Banks are motivated to transfer the cost imposed by reserve requirements via attempts to either pay depositors less or charge borrowers more or both - by widening the loan-deposit rate spread (Montoro and Moreno, 2011). This rests on the implicit assumption that the burden can be passed through.

Hein and Jonathan (2002) point out that along with the widely accepted view that reserve requirements act as a tax on banks, there is widespread disagreement that as to who bears the tax and who benefits when the tax is reduced. Black (1975), Fabozzi and Thurston (1986) argue that the reserve requirement tax is passed on to depositors of reservable instruments in the form of lower yields (Glocker and Towbin, 2012; Carrera and Vega, 2012). Some authors (Osborne and Zaher, 1992; Cosimano and McDonald, 1998; and Stewart and Hein, 2002) provide evidences suggesting that increases (reductions) in reserve requirements lead to lower (higher) bank stock prices, which means at least a portion of the tax is passed on to bank shareholders.

Cargill and Mayer (2005) find that banks do not respond to the changes in reserve requirements essentially by changing their excess reserves, instead, banks meet a substantial part of their increased reserve requirements by reducing their earning assets, including loans. They prove that the increase in reserve requirements reduces the availability of bank credit.

The effects of reserve requirements on the availability of credit is determined by the banking system's market structure (Reinhart and Reinhart, 1999), the degree of financial 
development, and the design of reserve requirements themselves. In general, changes in reserve requirements would pass-through wholly or in part to lending interest rates in those markets where banks have some monopoly power or where financial frictions are in place (Glocker and Towbin, 2012). The extent of this pass-through is depended on the remuneration set for reserve requirements (Hoffmann and Löffler, 2014).

Tovar, Garcia-Escribano, Martin (2012) consider that reserve requirements can help smooth credit growth for managing the credit cycle. In the upswing, rise in reserve requirements may increase lending rates, slowdown credit, and limit excess leverage of borrowers in the economy (Kasyhap and Stein, 2012). In the downswing, it can ease liquidity constraints in the financial system, thus operating as a liquidity buffer.

As for the process how reserve requirements affect the credit and real economy, Koray, Mahir, Selva, Hakan, Pınara (2014) explore a new channel called "liquidity channel" interpreting the interaction between reserve requirements and bank lending behavior, which tells a decline in bank liquidity and loan supply due to an increase in reserve requirements. Glocker and Towbin (2015) point out that bank lending channel is the main transmission mechanism for reserve requirement policy. According to bank lending channel, monetary policy actions can alter the supply of bank loans by changing bank reserves, and thus on the real economy (Kashyap and Stein, 1994). By lowering bank reserves, contractionary policy can decrease the core deposit funding of bank loans (due to reserve requirements) (Van Den Heuvel, 2002). If some banks (such as small banks) are unable to raise nonreservable funds to continue lending, policy will decrease their loan supply and affect the bank-dependent borrowers. Decreases in either loan supply or loan demand lead to reduced investment and consumption expenditures (Kishan and Opiela, 2000).

Ma, Yang and Liu (2011) argue that the PBC finds it easier to reach consensus on reserve requirements than interest rate decisions and enjoys greater discretion in applying this tool in recent years. The effects of reserve requirements should be explored in conjunction with other policy actions. Depending on the policy mix, higher reserve requirements tend to signal a tightening bias, to squeeze excess reserves of banks, to push market interest rates higher, and to help widen net interest spreads, thus tightening domestic monetary conditions. It is well known that reserve requirement is seemed as a tax burden on banks. Banks appear to pass through a big part of the burden to their customers, mostly depositors and small and medium-sized enterprises (SMEs). Yet bank shareholders may also bear part of the burden, if wider margins and spreads in part reflect increased risk premium.

Gray (2011) gives a simple description of differentiated reserve requirement ratio. Gray (2011) indicates that most of countries use a single reserve requirement rate for all reservable liabilities, a few countries use differentiated reserve requirements ratio with clear and achievable goals. Historically, some central banks have applied differential reserve requirements ratio to different types of banks (such as the United States set reserve 
requirements ratio based on geographic distinctions among member banks and the level of deposits during 1966-1972). This would appear to reflect the taxation aspect of unremunerated reserves, and implies a subsidy to those banks which have a lower reserve requirement.

Tovar et al. (2012) point out that reserve requirements can serve as a tool for credit allocation to ease liquidity pressures (Mora, 2014). At times of stress, an asymmetric use of reserve requirements across instruments, sectors and financial institutions can help direct credit to ease liquidity constrains in specific sectors of the economy.

To our knowledge, no literature tests the effects of DRRR policy on different regions in China. We will examine the effects of DRRR policy on the disaster region in China. The effect, if significant, may have strong implication on future China's monetary policy structure, particularly with regards to China's efforts to reduce regional disparities across China.

\section{METHODOLOGY}

The main purpose of this study is to check the role of DRRR policy on the outputs of the quake-stricken counties in Sichuan province. In May, 2008, a big earthquake happened in Sichuan provinces and made a lot of damages. To help the recovery of the earthquakestricken areas, the PBC decided to implement a preferential DRRR policy to corporate financial institutions in 39 most badly hurt counties. Financial institutions in other counties ${ }^{4}$ which suffer relatively small losses still apply the normal RRR. As we expect a preferential DRRR can promote a more quickly economic recovery than the normal RRR, we also randomly select 39 counties in Sichuan province from the other 142 counties which do not enjoy DRRR policy as our cases. We will examine the role of DRRR policy on the 39 earthquake-stricken counties and that of normal RRR on the other 39 counties to make a comparison in order to check whether or not the DRRR policy can promote the GDP growth more in the quake-stricken 39 counties than normal RRR policy implemented in the other 39 counties. The estimation period is the implementation period of the DRRR policy during 2008-2011.

We construct our model mainly based on the expenditure approach of GDP. As well known, GDP mainly contains four parts: government expenditure, investment, consumption and net exports. As these 78 counties in Sichuan province belong to the less developed western region, far from the coastal areas, there are very little or even no exports in these counties. We neglect net exports in our model. We divide investment into two parts: in the first part, the funds of investment are from bank loans, in the second part, the funds are from other sources. According to bank lending channel, we know that

\footnotetext{
${ }^{4}$ Sichuan province is a western province which has the biggest population (80.76 million persons) in China. It totally has 181 counties, cities at county level and districts under city administration.
} 
reserve requirement ratio can affect loans and the change of loans can influence investment, and finally will affect the real economy. We assume that the DRRR can affect investment through loans, thus we introduce an interaction item: DRRR*Loans, into GDP equation. We assume that the interaction item mainly affects the real economy and want to measure the influence of this interaction item on the GDP. Therefore, we get our model like this:

$G D P_{i t}=a_{i}+b_{i} G O V_{i t}+c_{i} L O A N_{i t}+\alpha_{i} D R R R_{i t} * L O A N_{i t}+\beta_{i} O I_{i t}+\gamma_{i} \operatorname{CONS}_{i t}+e_{i t}$

Where $G D P_{i t}$ is the GDP of 39 counties in Sichuan province, $\mathrm{t}=2008,2009,2010$ and 2011. $\mathrm{i}=1,2, \ldots, 39$. The $L O A N_{i t}$ is the total loan of each county. $G O V_{i t}$ is government expenditure measured by the local government intra-budgetary ordinary expenditure of each county. OI $_{i t}$ donates the investment whose funds are from other sources (except bank loans) measured by total investment in fixed assets (minus bank loans) of each county. $C O N_{i t}$ represents consumption measured by total retail sales of consumer goods in each county. These variables are real variables adjusted by the CPI index $(2008=100)$ in logarithm except (DRRR and RRR). DRRR $R_{i t}$ is Differentiated Reserve Requirement Ratio. $R R R_{i t}$ is Reserve Requirement Ratio. As the counties in Sichuan province are less developed areas located in inland China with no or very little FDI, we do not include FDI as an independent variable in our equation. $e_{i t}$ are residuals.

We will use panel data model to estimate this equation. The data cover 78 counties in Sichuan province from 2008 to 2011. Firstly, we will estimate the model for the 39 earthquake-badly-hurt counties enjoying the DRRR policy in Sichuan province, and then we estimate the model for the other 39 counties with normal RRR policy in Sichuan province. We will compare the coefficient: $\alpha_{i}$ to check the effects of DRRR (RRR) policy on the GDP growth in the counties with preferential DRRR policy and counties with normal RRR policy.

In panel data analysis, we estimate three models: pooled regression model, fixed effects model and random effects model. For pooled regression model, we pool all the observations in OLS regression. When using fixed effects model we assume that something within a county may impact or bias the independent and dependent variables and we need to control for this. This is the rationale behind the assumption of the correlation between county's error term and independent variables. Fixed effects remove the effect of those time-invariant characteristics from the independent variables so we can assess the independent variables' net effect. Another important assumption of the fixed effects model is that those time-invariant characteristics are unique to the individual and should not be correlated with other individual characteristics. Each county is different therefore the entity's error term and the constant (which captures individual characteristics)

\footnotetext{
${ }^{5}$ For 39 earthquake-stricken counties, the interaction part is DRRR*Loan. For the other 39 counties, the interaction part is RRR*loans.
} 
should not be correlated with the others. If the error terms are correlated then fixed effects is not suitable since inferences may not be correct and we need to model that relationship probably using random effects, this is the main rationale for the Hausman test.

The rationale behind random effects model is that, unlike the fixed effects model, the variation across counties is assumed to be random and uncorrelated with independent variables included in the model. The crucial distinction between fixed and random effects is whether the unobserved individual effect embodies elements that are correlated with the regressors in the model, not whether these effects are stochastic or not (Greene, 2008, p.183). If we have reason to believe that differences across counties have some influence on our dependent variable, then we should use random effects. An advantage of random effects is that we can include time invariant variables. In the fixed effects model these variables are absorbed by the intercept.

To decide between fixed or random effects we can run Hausman test where the null hypothesis is that the preferred model is random effects model VS the alternative the fixed effects (see Greene, 2008, chapter 9). It basically tests whether the unique errors are correlated with the regressors, the null hypothesis is they are not.

\section{EMPIRICAL RESULTS}

This study uses Pooled Ordinary Least Squares (POLS) to estimate the pooled regression model, uses within estimator to estimate the fixed effects and Generalized Least Squares (GLS) to estimate random effects model. We also provide the first difference estimator for model estimation. The results are reported in Table 1.

In Table 1, we estimate model A for the 39 earthquake badly hurt counties with DRRR policy, model B for the other 39 counties with normal RRR policy in Sichuan province. At the first glance, we can see the coefficients of the interaction part DRRR*LOAN of model $\mathrm{A}$ is bigger than that of model $\mathrm{B}$ in all regressions.

Then we run the Likelihood ratio test and Hausman test to see which model is the best one. For model A, first we run the Likelihood ratio test, the cross-section F-statistic is 29.4352 , the P-value is 0.0000 , so we reject the null hypothesis that the proper model is pooled regression model. Then we run the Hausman test to compare the fixed effects and random effects, if the Hausman test rejects the null hypothesis, the fixed effects model (entity fixed effects model) is appropriate, or the random effects model is estimated (Hausman, 1978). The Chi-Sq. Statistic for model A is 19.3821 and P-value is 0.0016, thus we reject the null hypothesis, the final model is fixed effects model. In model B, for Likelihood ratio test, the cross-section F-statistic is 88.2973, the P-value is 0.0000 , for the Hausman test, the Chi-Sq. Statistic is 28.0772 and P-value is 0.0000 , the null hypothesis 


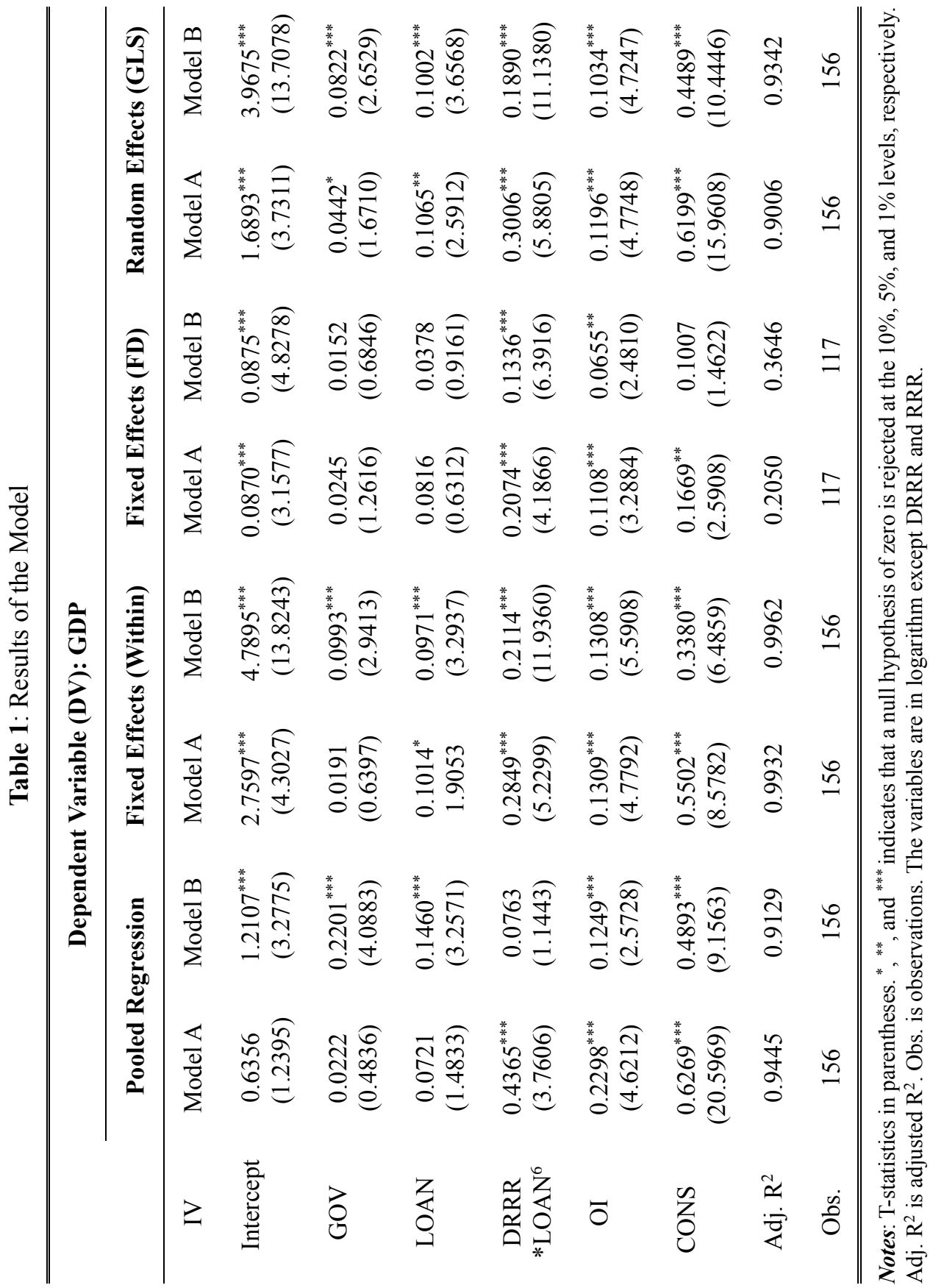

${ }^{6}$ For Model B, the interaction part is $R R R * L O A N$. 
can be rejected and we choose the fixed effects model (entity fixed effects model) as the best model.

For fixed effects model (within estimator), according to Table 1 we can see in model A (the earthquake-stricken counties), the coefficient of government expenditure is positive and non-significant. The coefficients of other independent variables are both positive and statistically significant. In model B, all the coefficients are positive and significant. The coefficient of the interaction part is the combined effect of the DRRR and loans on the GDP. This coefficient in model A is bigger than that in model B (fixed effects model). Ceteris paribus, considering all these 78 counties are in the same province Sichuan, located in the adjacent places, almost share the same economic development level, thus we can say that it is the DRRR policy which mainly causes the difference. In earthquakestricken counties, the combined effect of lower DRRR and more loans is about $34.77 \%$ bigger than that in the other 39 counties, indicating that the preferential DRRR in the earthquake-stricken counties is effective and does can help the economy of the less developed disaster counties to gain more growth than the normal RRR in other counties. We also provide the results of the first difference model (Table 1) and estimate the fixed effects model using Least Squares Dummy Variable (the results are available on request), the results are rather stable and confirm our finding.

\section{CONCLUSION}

This study uses panel data analysis to examine the effects of DRRR policy on the earthquake-stricken area during 2008-2011. For this purpose, we make a comparison between 39 earthquake-badly-hurt counties with preferential DRRR policy and the other 39 counties with normal RRR policy in Sichuan province. The results confirm our hypothesis that the preferential DRRR policy really can quicken the recovery process of the earthquake-stricken counties than the normal RRR in other counties.

Our results have a profound policy implication. As China is a huge country and the regional disparity is obvious (Lau, 2010; Fan, Kanbur and Zhang, 2011; Pedroni and Yao, 2006), common monetary policy may have regional effects on different provinces and these regional effects may increase the gap among regions in China. This study provides an empirical proof that we can narrow the gap from the perspective of monetary policy. When the PBC formulates and implements the common monetary policy, they should take the different effects of monetary policy into account. To reduce the regional effects of monetary policy, the PBC can try to implement differentiated monetary policy instrument so as to make a structural adjustment of the economy. This DRRR policy is a new try by the PBC. Our finding proves that the DRRR policy can promote the economy growth of the disaster area much quickly than normal RRR. Then we can suggest that the PBC can consider expanding to apply this preferential DRRR policy to less developed provinces 
(Such as some provinces in the Middle and West) or some rural areas in order to reduce the regional disparity and promote a more coordinated regional economic development.

This type of instrument gives certain flexibility to monetary policy. The PBC can adjust differential reserve requirement ratio according to different conditions. The PBC has also applied this DRRR policy into different banks, such as large banks and Small \& Medium sized banks. If we can prove that the DRRR policy also has significant effects on promoting S\&M sized banks to make more loans to S\&M sized enterprises (another paper), then the implementation of differentiated monetary policy instrument to make structural adjustment of economy has more meaning to some extent. These actions reflect that the PBC starts to use differentiated monetary policy to guide credit funds flow to the area which government policy focus on. Monetary policy begins to play a role in adjusting and optimizing economic structure.

Since 2014, the PBC has started to apply structural monetary policy in order to boost economic restructuring and support the real economy. Targeted RRR cuts (the same meaning to the DRRR) ${ }^{7}$ is a normal tool of structural monetary policy which is frequently used by the PBC. Targeted RRR cuts shows the government's creativity as it aims at optimizing the financial structure. In particular, it will help underdeveloped areas and smaller businesses which have historically struggled with a lack of credit availability. For example, the PBC has cut the RRR several times by 0.5 percentage points for banks engaged in proportionate lending to agriculture-related businesses and small and microsized companies, for county-level rural commercial banks and rural credit cooperative unions in rural areas, in efforts to boost credit structure and enhance financial support to the real economy since 2014.

However, the implementation period of differentiated monetary policy instrument is limited. It can be implemented when there exists regional disparity in one country and common monetary policy has regional effects across regions. Once the regional economies become balanced, the differentiated monetary policy instrument no longer apples, instead, common and unified monetary policy will be proper.

Our study also has some limitations. For the model, in fact, the best data used in the model is actually monthly or seasonal data, but due to the data limitation, we can only get the annual data. For panel data analysis, four year's data may be too short. These limitations will be solved when the data are available in the future. Moreover, only one case study (DRRR policy in earthquake-stricken counties) may be not enough to confirm the role of

\footnotetext{
${ }^{7}$ Targeted RRR cuts has the same meaning to the DRRR, it is another word of DRRR. As DRRR means the PBC implements higher or lower RRR than normal RRR in certain region or certain kind of financial institutions. Targeted RRR cuts implies that the PBC applies lower RRR to certain region or certain kind of financial institutions in order to support the real economy.
} 
DRRR policy, we need more proofs (such as DRRR policy on large banks and Small \& Medium sized banks).

\section{ACKNOWLEDGEMENTS}

The author declares that this paper has been supported by the 2015 Social Science Research Program of High Learning Institution in Hebei Province (Program Number: SQ15094), the 2015 Major Social Science Research Program of Educational Department of Hebei Province (Program Number: ZD201511), and the Comprehensive Strength Promotion Project of Midwest Universities (Hebei University) Sponsored by the Ministry of Education in China.

A version of the paper has been presented at and published in the proceedings of the 3rd International Conference on Rural Development and Entrepreneurship, Baoding City, Hebei Province, China, 9th -11th, May, 2015. The authors would like to thank the feedbacks from the participants of the 3rd International Conference on Rural Development and Entrepreneurship and the useful comments from the reviewers of International Journal of Business and Society. All the remaining errors are the authors.

\section{REFERENCES}

Black, F. (1975). Bank Funds Management in an Efficient Market. Journal of Financial Economics, 2(4), 323-339.

Borio, C., \& Disyatat, P. (2009). Unconventional Monetary Policies: an Appraisa. BIS Working Papers, No. 292.

Cañón, C., \& Margaretic, P. (2014). Correlated bank runs, interbank markets and reserve requirements. Journal of Banking \& Finance, 49, 515-533.

Cargill, T. F., \& Mayer, T. (2006). The Effect of Changes in Reserve Requirements during the 1930s: The Evidence from Nonmember Banks. Journal of Economic History, 66(2), 417.

Carrera, C., \& Vega, H. (2012). Interbank Market and Macroprudential Tools in a DSGE Model. Serie de Documentos de Trabajo, 2012-014, Banco Central De Reserva Del Peru.

Cosimano, T. F., \& McDonald, B. (1998). What's Different among Banks? Journal of Monetary Economics, 41(1), 57-70.

Fabozzi, F. J., \& Thurston, T. B. (1986). State Taxes and Reserve Requirements as Major Determinants of Yield Spreads among Money Market Instruments. Journal of Financial and Quantitative Analysis, 21(04), 427-436.

Fan, S., Kanbur, R., \& Zhang, X. (2011). China's Regional Disparities: Experience and Policy. Review of Development Finance, 1(1), 47-56. 
Glocker, C., \& Towbin, P. (2012). Reserve Requirements for Price and Financial Stability: When Are They Effective? International Journal of Central Banking, 8(1), 115126.

Glocker, C., \& Towbin, P. (2015). Reserve Requirements as a Macro-prudential Instrument - Empirical Evidence from Brazil. Journal of Macroeconomics, 44, $158-176$.

Gray, S. (2011). Central Bank Balances and Reserve Requirements. International Monetary Fund, 11.

Greene, W. H. (2008). Econometric Analysis ( $6^{\text {th }}$ Edition Ed.). Upper Saddle River, N.J.: Wharton School Publishing.

Hausman, J. A. (1978). Specification Tests in Econometrics. Econometrica: Journal of the Econometric Society, 46(6), 1251-1271.

Hein, S. E., \& Jonathan, D. S. (2002). Reserve Requirements: A Modern Perspective. Economic Review-Federal Reserve Bank of Atlanta, 87(4), 41-52.

Hoffmann, A., \& Löffler, A. (2014). Low interest rate policy and the use of reserve requirements in emerging markets. The Quarterly Review of Economics and Finance, 54(3), 307-314.

Ireland, P. (2012). The Macroeconomic Effects of Interest on Reserves. NBER Working Papers, No. 18409.

Kashyap, A. K., \& Stein, J. C. (1994). The Impact of Monetary Policy on Bank Balance Sheets. National Bureau of Economic Research Working Paper Series, No. 4821. Kashyap, A. K., \& Stein, J. C. (2012). The Optimal Conduct of Monetary Policy with Interest on Reserves. American Economic Journal: Macroeconomics, 4(1), 266282.

Kishan, R. P., \& Opiela, T. P. (2000). Bank Size, Bank Capital, and the Bank Lending Channel. Journal of Money, Credit and Banking, 121-141.

Koray, A., Mahir, B., Selva, D., Hakan, K., \& Pınara, Ö. (2014). Reserve Requirements, Liquidity Risk, and Credit Growth. Koç University-TÜSIAD Economic Research Forum Working Paper Series, No. 1416.

Lau, C. K. M. (2010). New Evidence about Regional Income Divergence in China. China Economic Review, 21(2), 293-309.

Ma, G., Yan, X., \& Liu, X. (2011). China's Evolving Reserve Requirements. Discussion paper of Bank of Finland Institute for Economics in Transition, 30, 1-48.

Montoro, C., \& Moreno, R. (2011). The Use of Reserve Requirements as a Policy Instrument in Latin America. BIS Quarterly Review, March, 53-65.

Mora, N. (2014). Reason for Reserve? Reserve Requirements and Credit. Journal of Money, Credit and Banking, 46(2-3), 469-501.

Osborne, D. K., \& Zaher, T. S. (1992). Reserve Requirements, Bank Share Prices, and the Uniqueness of Bank Loans. Journal of Banking \& Finance, 16(4), 799-812.

Pedroni, P., \& Yao, J. Y. (2006). Regional Income Divergence in China. Journal of Asian Economics, 17(2), 294-315.

Peek, J., \& Rosengren, E. S. (1995). Bank Lending and the Transmission of Monetary Policy. Conference series-Federal Reserve Bank of Boston, 39, 47-79. 
Reinhart, C. M., \& Rogoff, K. S. (2013). Shifting Mandates: The Federal Reserve's First Centennial. American Economic Review: Papers \& Proceedings 2013, 103(3), 48-54.

Reinhart, V., \& Reinhart, C. (1999). On the Use of Reserve Requirements in Dealing with Capital Flow Problems. International Journal of Finance and Economics, 4(1), 27-54.

Stewart, J. D., \& Hein, S. E. (2002). An Investigation of the Effect of the 1990 Reserve Requirement Change on Financial Asset Prices. Journal of Financial Research, 25(3), 367-382.

Tovar, C., Garcia-Escribano, M., \& Vera Martin, M. (2012). Credit Growth and the Effectiveness of Reserve Requirements and Other Macroprudential Instrument in Latin America. IMF Working Paper, WP/12/142.

Van den Heuvel, S. J. (2002). Does Bank Capital Matter for Monetary Transmission? Economic Policy Review, 8(1), 259-265.

Walsh, C. (2012). Discussion of Reserve Requirements for Price and Financial Stability: When are they Effective? International Journal of Central Banking, 8(1), 65-114. 